\section{Infected appendiceal mucocele presenting as pyrexia of unknown origin}

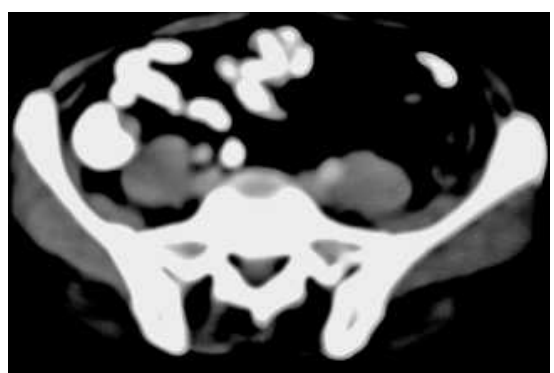

Fig. 1 Computed tomographic scan of the abdomen, showing a smooth, rounded indentation on the medial wall of the cecum.

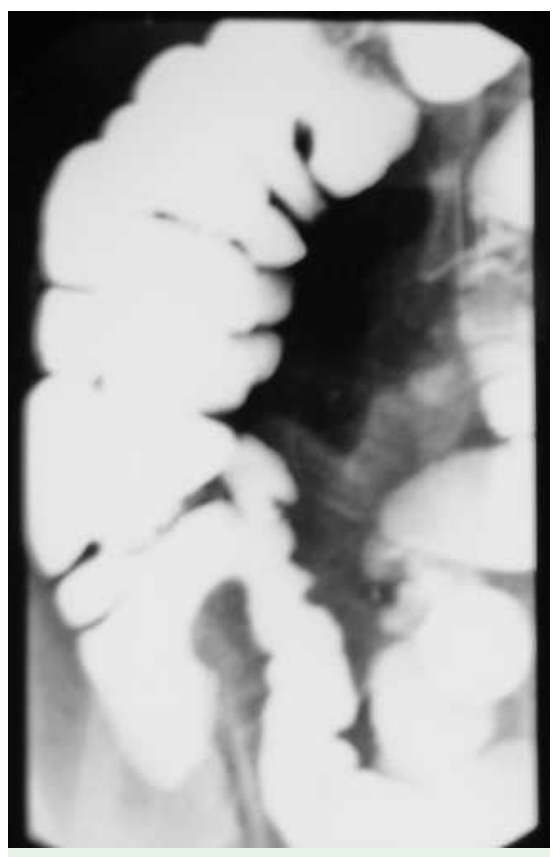

Fig. 2 Barium study showing indendation at the base of the cecum, along the medial wall.

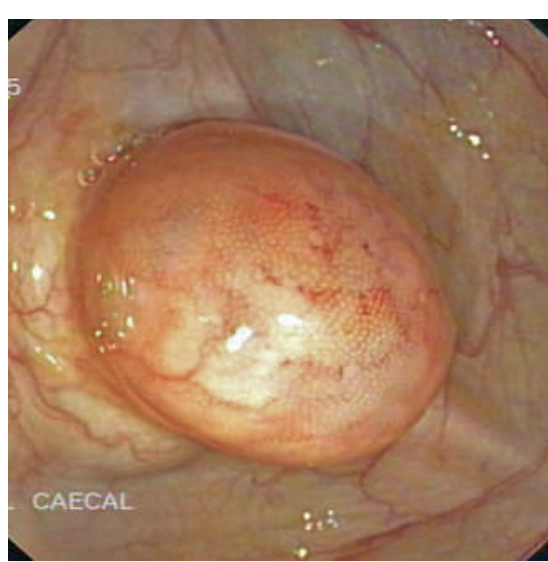

Fig. 3 Colonoscopy revealed a smooth, rounded lesion in the cecum; the appendix is not visualized.
A mucocele of the appendix is defined as dilatation of the appendiceal lumen secondary to a variety of underlying pathological processes. Its presentation as pyrexia of unknown origin (PUO) has not been reported before. A 65-year-old man presented with a 3-month history of high-grade fever. Clinical examination and initial work-up for PUO was unremarkable. Contrast-enhanced abdominal computed tomography detected a welldefined, smooth, hypodense lesion at the base of the cecum ( Fig. 1). A smooth filling defect, $1.5 \mathrm{~cm} \times 1.5 \mathrm{~cm}$ in size, was seen on barium meal and follow through (๑ Fig. 2). At colonoscopy, a smooth, in-

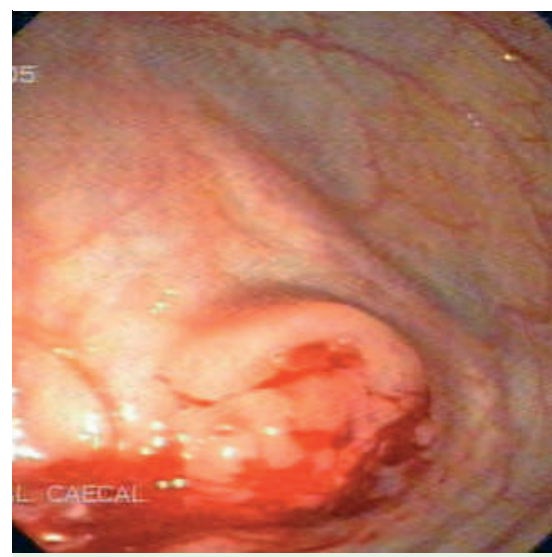

Fig. 4 On biopsy, there was a gush of mucopurulent fluid and the lesion disappeared. The appendix can now be clearly seen in this colonoscopic view, suggesting that the lesion was related to the appendix.

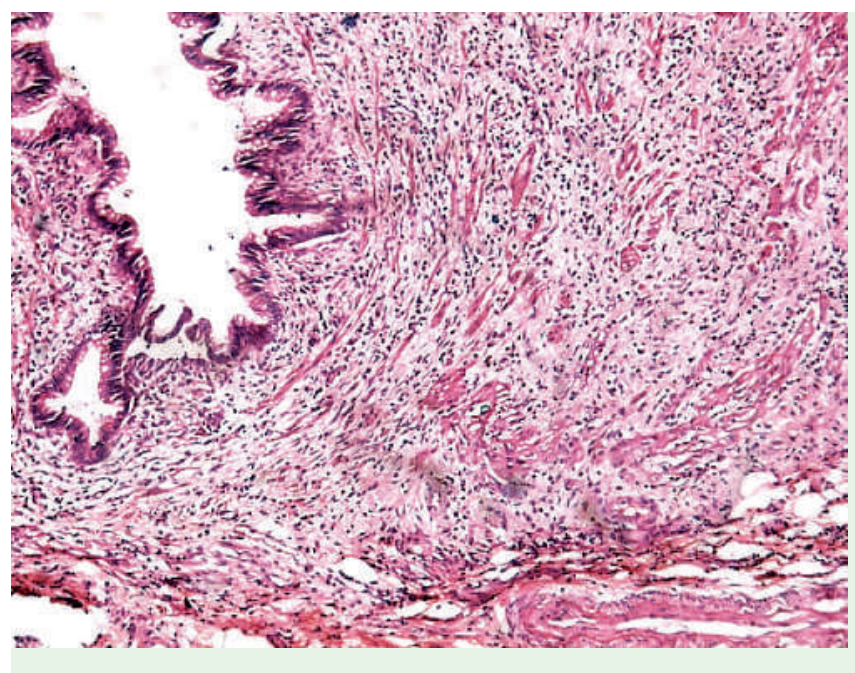

Fig. 5 A low-power photomicrograph of the appendix, showing a mucinous type of epithelium. The lamina propria, submucosa, muscularis mucosa, and serosa are interspersed with pale eosinophilic material (mucin), separating the muscle fibers. As well as the mucin there is dense and diffuse infiltration with chronic inflammatory cells (hematoxylin and eosin stain, original magnification $\times 140$ ). 
H. Udawat ${ }^{1}$, A. Sharma ${ }^{2}$, U. Dutta ${ }^{1}$,

T. D. Yadav ${ }^{3}$, K. Vaiphei ${ }^{4}$, S. Singh ${ }^{2}$,

R. Kochhar ${ }^{1}$

${ }^{1}$ Department of Gastroenterology, Postgraduate Institute of Medical Education and Research, Chandigarh, India

2 Department of Internal Medicine, Postgraduate Institute of Medical Education and Research, Chandigarh, India

3 Department of General Surgery, Postgraduate Institute of Medical Education and Research, Chandigarh, India

${ }^{4}$ Department of Histopathology, Postgraduate Institute of Medical Education and Research, Chandigarh, India

\section{References}

1 Dachman A, Lichtenstein J, Friedman A. Mucocele of the appendix and pseudomyxoma peritonei. AJR Am J Roentgenol 1985; 144: 923-929

2 Caspi B, Cassif E, Auslender R et al. The onion skin sign: a specific sonographic marker of appendiceal mucocele. J Ultrasound Med 2004; 23: 117-121

3 Horgan J, Chow P, Richter J et al. CT and sonography in the recognition of mucocele of appendix. AJR Am J Roentgenol 1984; 43: 959-962

4 Hamilton DL, Stormont JM. The volcano sign of appendiceal mucocele. Gastrointest Endosc 1989; 35: 453-456
Bibliography

DOI $10.1055 / \mathrm{s}-2007-966704$

Endoscopy 2007; 39: E113-E114

(c) Georg Thieme Verlag KG Stuttgart · New York . ISSN 0013-726X

\section{Corresponding author}

\section{U. Dutta, MD, DM}

Department of Gastroenterology

Postgraduate Institute of Medical Education and Research

Chandigarh 160012

India

Fax: +91-172-2744401

ushad@satyam.net.in 